\title{
Puesta en marcha de un lugar de memoria en Bucaramanga: la experiencia del Archivo Oral de Memoria de las Víctimas*
}

\author{
Diana del Pilar Novoa Sanmiguel ${ }^{* *}$ \\ Diego Andrés Escamilla Márquez ${ }^{* * *}$
}

\begin{abstract}
Recibido: 24 de junio de 2018
Evaluado: 14 de septiembre de 2018

Aceptado: 23 de octubre de 2018
\end{abstract}

Citar como: Novoa Sanmiguel, D. del P.y Escamilla Márquez, D. A. (2019). Puesta en marcha de un lugar de memoria en Bucaramanga: la experiencia del Archivo Oral de Memoria de las Víctimas. Hallazgos, 16(31), 41-60. Doi: https://doi.org/10.15332/ s1794-3841.2019.0031.02

\section{Resumen}

El artículo busca abordar algunos de los alcances, problemas y cimientos teóricos y metodológicos del proceso de construcción y consolidación del Archivo Oral de Memoria de las Víctimas (Amovi) en la ciudad de Bucaramanga, en Colombia. Esta institución nace como una iniciativa académica de investigación y difusión de testimonios y otras formas de memoria de las víctimas. El Amovi pretende conservar la memoria de las víctimas del conflicto armado asentadas en la ciudad y sus alrededores, y aportar a la comprensión del referido conflicto, a la vez que busca entrar en la disputa por los sentidos y las interpretaciones del pasado reciente colombiano. El Amovi ha adelantado esta investigación desde el enfoque metodológico de la historia oral, con el objetivo de acceder a las esferas individuales y colectivas del conflicto, entendiéndolas en relación con los marcos sociales dentro de los que se producen. Se busca asimismo que las entrevistas y otros documentos producidos se constituyan en alternativas documentales válidas para los estudios sociales, al tiempo que se hace contrapeso a los relatos hegemónicos existentes.

\footnotetext{
El presente artículo es una reflexión alrededor de los resultados obtenidos por el Grupo de Investigación Hared (Historia, Archivística y Redes de Investigación) en el proyecto de investigación titulado "Puesta en marcha de un archivo oral de memoria en el Área Metropolitana de Bucaramanga. Verdades no contadas: el conflicto armado colombiano desde la memoria de las víctimas. Fase II", financiado por la Universidad Industrial de Santander entre 2016 y 2017.

** Historiadora, Universidad Industrial de Santander; candidata a Magister, Universidad de la Plata (programa Historia y Memoria). La Plata, Argentina. e-mail: diananovoa4@gmail.com; ORCID: https://orcid.org/0000-0001-8760-5384

*** Historiador y Archivista de la Universidad Industrial de Santander; candidato a Magister, Universidad Bicentenaria de Aragua (programa Planificación Educativa). La Plata, Argentina. e-mail: diegoescamillag12@yahoo.com.ar; ORCID: https://orcid.org/0000-0002-8866-6629
} 
La creación del Amovi ha querido garantizar el acceso y resguardo de documentos escritos y orales, así como se protegen a los productores de estos, asumiendo la tarea de posicionar las voces de las víctimas como parte de las iniciativas de memoria en la ciudad de Bucaramanga y Colombia, mientras se enfrentan las dificultades de un conflicto armado que no cesa del todo.

Palabras clave: memoria histórica, conflicto armado interno colombiano, víctimas, historia oral, archivos orales. 


\section{Start-up of a memoir place in Bucaramanga: The experience of the Oral Archive of the Victims' Memoirs}

Received: June 24, 2018

Evaluated: September 14, 2018

Accepted: October 23, 2018

\section{Abstract}

The article seeks to address some of the scope, problems and theoretical and methodological foundations of the process of construction and consolidation of the Oral Archive of the Victims' Memoirs (Amovi) in the city of Bucaramanga, in Colombia. This institution was born as an academic initiative of research and dissemination of testimonies and other forms of victims' memoirs. The Amovi aims to preserve the victims of armed conflict memoirs in the city and its surroundings, and contribute to the understanding of the conflict, while seeking to enter into the dispute over the meanings and interpretations of the recent Colombian past. The Amovi has conducted this research from the methodological approach of oral history, with the purpose of accessing the individual and collective spheres of the conflict, understanding them in relation to the social frameworks in which they occur. It also seeks that the interviews and other documents produced constitute valid documentary alternatives for social studies, while counterbalancing the existing hegemonic narratives. The creation of the Amovi has wanted to ensure the access and safeguard of written and oral documents, as well as protect the creators thereof, assuming the task of positioning the voices of the victims as part of memoir initiatives in the city of Bucaramanga and Colombia, while facing the difficulties of an armed conflict that does not cease altogether.

Keywords: historical memory, Colombian internal armed conflict, victims, oral history, oral archives. 


\section{Implementação de um lugar da memória em Bucaramanga: a experiência do Arquivo Oral da Memória das Vítimas}

\section{Resumo}

$\mathrm{O}$ artigo procura abordar alguns dos alcances, problemas e alicerces teóricos e metodológicos do processo de construção e consolidação do Arquivo Oral da Memória das Vítimas (Amovi) na cidade de Bucaramanga, na Colômbia. Esta instituição nasceu como uma iniciativa acadêmica de pesquisa e difusão de testemunhos e outras formas de memória das vítimas. O Amovi pretende conservar a memória das vítimas do conflito armado estabelecidas na cidade e seus arredores e aportar à compreensão do conflito, ao mesmo tempo em que procura entrar na disputa pelos sentidos e interpretações do passado recente colombiano. O Amovi tem adiantado esta pesquisa desde o enfoque metodológico da história oral, com o objetivo de acessar às esferas individuais e coletivas do conflito, e entendê-las em relação com os marcos sociais dentro dos quais se produzem. Procura-se igualmente que as entrevistas e outros documentos produzidos constituam-se em alternativas documentais válidas para os estudos sociais, ao mesmo tempo em que se faz contrapeso aos relatos hegemônicos existentes. A criação do Amovi tem querido garantir o acesso e resguardo de documentos escritos e orais, assim como se protegem aos produtores destes, assumindo a tarefa de posicionar as vozes das vítimas como parte das iniciativas de memória na cidade de Bucaramanga e Colômbia, enquanto se enfrentam as dificuldades de um conflito armado que não acaba completamente.

Palavras-chave: memória histórica, conflito armado interno colombiano, vítimas, história oral, arquivos orais.

Recebido: 24 de jhuno de 2018

Avaliado: 14 de setembro de 2018

Aceito: 23 de outubro de 2018 


\section{INTRODUCCIÓN}

El Archivo Oral de Memoria de las Víctimas (Amovi) de la Universidad Industrial de Santander (UIS) tiene sus orígenes en 2011, cuando en el proyecto de investigación Estudio de trayectorias de vida de personas en situación de desplazamiento forzado interrelacionadas en el barrio Café Madrid del municipio de Bucaramanga (Suárez, Báez, Ardila y Rueda, 2010), un grupo de profesionales de distintas campos de las ciencias sociales ubicó sus intereses de estudio en los testimonios de las víctimas de desplazamiento forzado que habitaban uno de los barrios más empobrecidos de Bucaramanga. Fueron cerca de dos años de trabajo en los cuales, además de la producción y el análisis de veinticinco testimonios de víctimas y la correspondiente elaboración de sus trayectorias de vida, se realizaron jornadas de socialización de los resultados de la investigación con organizaciones de víctimas, defensores de derechos humanos, entes estatales e instituciones académicas de la ciudad.

Toda la labor realizada por este proyecto de investigación fue registrada en actas de campo, informes, audios, transcripciones, análisis categoriales y demás formatos de recolección de información, que en su momento permitieron la sistematización de la experiencia, pero que luego constituyeron un cúmulo de documentación susceptible de conservar, no solo por su importancia académica, sino también por su valoración sociopolítica, toda vez que sus contenidos refieren la memoria de las víctimas del conflicto colombiano, así como sus reivindicaciones más importantes. En estos años de surgimiento, el Amovi significó la apuesta de hacer memoria, pero con un agregado muy importante: la perspectiva archivística. De este modo, el reto de esta naciente institución no solo lo configuró la producción de memoria en sí, sino el hecho de preservar, organizar y posibilitar el acceso de la documentación sobre el conflicto, sumamente necesaria para dinamizar los ejercicios de memoria, no solo en el presente, sino también en el futuro.

El Amovi contó con una fase inicial de tres años, financiada por el Departamento Administrativo de Ciencia, Tecnología e Innovación (Colciencias) y una segunda fase de seis meses financiada por la UIS. Durante estos años de actividad, las labores de acopio, organización, conservación, difusión e investigación fueron adelantadas siguiendo la metodología de la historia oral, las técnicas archivísticas y el enfoque de memoria histórica razonada. ${ }^{1}$ Este enfoque el Amovi lo ha venido posicionando en contraposición a los ejercicios de memoria adelantados por el Estado colombiano en los cuales las víctimas han sido simples narradores o aportadores de datos concretos o, a lo sumo, ejemplos mediatizados de superación personal.

En la actualidad, el Amovi cuenta con más de 300 testimonios en audio que corresponden a entrevistas realizadas por sus investigadores y pasantes o donadas por proyectos externos. Posee también una pequeña estructura física en la UIS, que, además de servir de lugar de trabajo para

1 "El fin de la memoria histórica razonada es hacer memoria desde los análisis del conflicto realizados conjuntamente por víctimas e investigadores, mediante ejercicios de conversación, contextualización y crítica. Con ello se pretende que las víctimas sean sujetos activos de la historia, no solo por su participación en la rememoración del pasado, sino también por sus acciones de cara al futuro, pues el fondo de esta propuesta es una memoria que comprenda el pasado para que víctimas y sociedad en general puedan contribuir a la resolución de las problemáticas sociales vigentes" (Escamilla y Novoa, 2017a, p. 70). 
el equipo de investigación, ha hecho las veces de centro de documentación, con más de mil libros, revistas e informes, que están dispuestos para préstamo y consulta de la comunidad universitaria y de la ciudadanía local. Se elaboraron igualmente formatos de donación, consulta y préstamo, así como un reglamento de funcionamiento. A pesar de que la mayoría de la documentación es de carácter oral (y digital), el Amovi posee quince fondos con documentación física en soporte papel y fotografías, que poco a poco han entrado a ampliar el acervo del archivo y que, junto con el resto de documentación, están registrados en los inventarios y cuadros de clasificación.

Durante estos años de ejecución de proyectos, el Amovi ha llevado a cabo ponencias en congresos internacionales y nacionales, ha organizado seminarios y encuentros académicos, ha realizado talleres de capacitación, ha consolidado un semillero de investigación, ${ }^{2}$ ha publicado varios artículos en revistas indexadas y dos libros (con 55 trayectorias de vida de víctimas del conflicto colombiano), ha llevado a cabo eventos artísticos y conmemorativos y ha contribuido a la creación de lugares de memoria en la ciudad de Bucaramanga, entre otras tareas, que buscan construir memoria histórica más allá de los meros objetivos académicos y sumarse a las acciones reivindicativas que demandan verdad, reparación y justicia. ${ }^{3}$

2 Nombre con el que se conoce en Colombia a los grupos de investigación conformados, principalmente, por estudiantes y que antecede a los grupos de investigación de profesores e investigadores expertos.

3 Todas estas actividades pueden ser consultadas en la siguiente página institucional del Amovi https://www.uis.edu.co/webUIS/es/ amoviUIS/index.html

\section{¿Por qué hacer memoria de LAS VÍCTIMAS DEL CONFLICTO ARMADO INTERNO ${ }^{4}$ EN Colombia?}

Plantearse la necesidad de hacer memoria con las víctimas del conflicto armado colombiano precisa, de antemano, reconocer las características propias de este tipo de ejercicios, pues no se trata de cualquier memoria, o, por lo menos, de la memoria que podría hacerse de manera tradicional recurriendo a la narración de los medios de comunicación, los organismos judiciales o los victimarios, sino que, por el contrario, se trata de una memoria que apela a las historias y los recuerdos de quienes están en la otra orilla del poder: las víctimas, los principales agraviados de la guerra, civiles que representan más del $80 \%$ de los afectados del conflicto (Centro Nacional de Memoria Histórica [CNMH], 2013, p. 32).

Que las víctimas sean civiles no significa que sean apolíticas. Archila (2012) ha identificado a las víctimas con los llamados sectores subalternos, pues evidencia en ellas una disposición a salir de la condición que las vence, excluye y victimiza, en busca de, entre otras cosas, "controlar su presente desde el reconocimiento de su pasado y

4 Dentro del Amovi, se ha privilegiado la expresión conflicto armado interno, para referirnos al tipo de confrontación que se ha desarrollado en Colombia durante los últimos cincuenta años, entre el Estado colombiano y los grupos armados al margen de la ley (o entre estos mismos), tal como lo ha establecido el derecho internacional humanitario (Comité Internacional de la Cruz Roja [CICR], 2008). Esta expresión, mucho más acertada que las posiciones que enmarcan la violencia política dentro del discurso contra el "terrorismo", no es, sin embargo, suficiente. La complejidad del actual conflicto, sin duda, sobrepasa el mero aspecto humanitario, pero encontrar una nomenclatura que pueda sintetizar toda esta complejidad es casi imposible. De ahí que otras expresiones distintas de conflicto armado interno, como guerra, guerra civil, guerra interna, entre otras, sean también acepciones válidas a la hora de enunciar dicha complejidad. 
así pensar en un futuro distinto" (p. 2). Esta disposición reviste un significativo carácter político, pues alude a que las víctimas no son sujetos pasivos en la sociedad, sino que buscan intervenir en ella, en especial en lo concerniente a la construcción del relato del pasado, pugnando por dotar a este relato de significados que den cuenta de sus intereses y sentidos históricos, mediante la dignificación y reivindicación de sus anteriores luchas, lejanas o cercanas en el tiempo. Nada puede ser más político que esta pretensión.

Este carácter político del movimiento de víctimas en Colombia ha redundado también en la producción de una memoria política, pues, como lo expresa Calveiro, la memoria, como asignación de sentidos a fragmentos de una experiencia antigua articulados con los nuevos sentidos del presente para su uso aquí y ahora, expresa la capacidad de resistencia y de demanda de justicia de las comunidades que elaboran dicha memoria (2017, p. 3). En otras palabras, para estos sectores mancillados, el ejercicio de memoria no implica solo el cumplimiento de un derecho, ${ }^{5}$ sino también una acción concreta de lucha, mediante la cual el significado del pasado y su consecuente sentido del presente se enlaza con reclamos de justicia, reparación y superación de los hechos dolorosos.

En este sentido, las víctimas del conflicto en Colombia, no solo intentan recordar hechos

5 El principio 2 del conjunto de principios para la protección y promoción de los derechos humanos mediante la lucha contra la impunidad correspondiente al derecho a la memoria explica que "el conocimiento por un pueblo de la historia de su opresión forma parte de su patrimonio" ("La administración de la justicia y los derechos humanos de los detenidos. La cuestión de la impunidad de los autores de violaciones de los derechos humanos (civiles y políticos). Informe final elaborado y revisado por M. Joinet en aplicación de la decisión 1996/119 de la Subcomisión"). acontecidos o seres queridos asesinados o desparecidos, sino también legitimar sus luchas e idearios, reafirmando de paso sus identidades colectivas y reivindicando la dignidad y el buen nombre de sus familiares, amigos, territorios y comunidades, pues la guerra no solo conllevó la desaparición física de cientos de miles de seres humanos y el desplazamiento de familias y comunidades enteras, sino también la tergiversación, el silenciamiento o el olvido de sus aspiraciones y acciones políticas, asunto que se ha traducido en la pérdida de referentes para la movilización y resistencia tanto de las víctimas sobrevivientes como de la sociedad colombiana en general. ${ }^{6}$

\section{El Estado Colombiano Y LOS HISTORIADORES EN LA CONSTRUCCIÓN DE MEMORIA DEL CONFLICTO}

En medio del desolador panorama de más de ocho millones de víctimas ${ }^{7}$ y de una guerra que, a pesar del esfuerzo por su superación, muestra nuevos matices, las comunidades de víctimas y organizaciones sociales de diversa índole (estudiantiles, sindicales, campesinas, feministas, humanitaristas y académicas) han adelantado durante años sus propios esfuerzos por hacer memoria. El Estado colombiano también ha asumido esta tarea, en especial a partir de la promulgación de la Ley 975/2005, de

6 No obstante, es necesario acotar, tal como lo afirma Acevedo (2012, pp. 68-69), que, en lo concerniente a los sectores subalternos, no todas las memorias producidas son contestatarias o disidentes, es decir, no todas desean entrar en la disputa política por el discurso hegemónico. Por otro lado, como lo hemos argumentado en otro trabajo, no todas las memorias que sí desean entrar en esta disputa tienen la capacidad de hacerlo (Escamilla y Novoa, 2017b, p. 507).

7 Según la Unidad para las Víctimas, el número de víctimas en el conflicto armado interno es de 8625631. 
25 de julio y de la Ley 1448/2011, de 10 de junio, despertando críticas según las cuales esta labor ha fungido más como un intento de memoria oficial que como un actuación objetiva, signada por la más perversa paradoja: uno de los mayores victimarios del conflicto armado (el Estado colombiano) haciendo memoria como si fuese una víctima o, a lo sumo, un ente neutral en el desarrollo y las consecuencias de este (Estrada, 2016, pp. 354-355).

Vale la pena preguntarnos cuál es el interés del Estado colombiano por ponerse a la cabeza de la construcción de memoria del conflicto. ¿Se debe acaso al simple cumplimiento de lo estipulado por mandatos nacionales e internacionales? ¿Obedece este interés a la necesidad de instrumentalizar la producción de memorias subalternas con el objetivo de neutralizarlas y unificarlas en un solo relato que sea fácilmente difundido (y aceptado) y que propicie la reconciliación en detrimento de las demandas sociales de transformación estructural? ¿Es posible esperar objetividad y autonomía desde los organismos estatales encargados de la memoria en lo que respecta a la responsabilidad del Estado en el conflicto? Tales interrogantes pretenden, más que respuestas inmediatas, abrir un debate concienzudo de lo que representan las actuales elaboraciones de memoria por parte de los organismos estatales. Jelin señala al respecto:

Una vez establecidas estas narrativas canónicas oficiales, ligadas históricamente al proceso de centralización política de la etapa de conformación de estados nacionales, se expresan y cristalizan en los textos de historia que se transmiten en la educación formal. Al mismo tiempo, se constituyen en los blancos para intentos de reformas, revisionismos y relatos alternativos. Porque la memoria nacional tiende a ser la de los vencedores, y habrá otros que, sea en la forma de relatos privados de transmisión oral o como prácticas de resistencia frente al poder, ofrecerán narrativas y sentidos diferentes del pasado, amenazando el consenso nacional que se pretende imponer. (2002, p. 41)

La crítica que plantean los relatos alternativos a las narrativas oficialistas puede encontrar, según la misma autora, cierta materialización en los llamados periodos de transición democrática o de apertura política. ${ }^{8}$ No obstante, en lo que respecta a la historia reciente de Colombia, tales transiciones o no han existido o son de por sí insignificantes, lo que supone una memoria estatal desmesuradamente imponente frente al papel de las otras memorias. Ante este contexto de memorias que claramente entran en disputa y de forma tan desigual, ¿cuál debería ser la tarea del investigador que busca adentrarse en la comprensión del conflicto armado desde y junto con las acciones de memoria de las víctimas?

Traverso (2007) explica que, si bien la historia y la memoria tienen un origen y motivación compartidos (la elaboración del pasado), la historia, como quehacer del historiador,

8 "El escenario político es de cambio institucional en el Estado y en la relación Estado-sociedad. La lucha se da, entonces, entre actores que reclaman el reconocimiento y la legitimidad de su palabra y sus demandas. Las memorias de quienes fueron oprimidos y marginalizados - en el extremo, quienes fueron directamente afectados en su integridad física por muertes, desapariciones forzadas, torturas, exilios y encierros- surgen con una doble pretensión, la de dar la versión "verdadera" de la historia a partir de su memoria y la de reclamar justicia. En esos momentos, memoria, verdad y justicia parecen confundirse y fusionarse, porque el sentido del pasado sobre el que se está luchando es, en realidad, parte de la demanda de justicia en el presente" (Jelin, 2002, p. 41). 
tiene la posibilidad de emanciparse de la memoria y, con pretensiones de objetividad y veracidad, convertirla en su objeto de estudio. Este oficio analítico puede ubicar la memoria en contextos más amplios con el fin de comprenderla y explicarla así como valorar sus características más importantes. Traverso destaca, por ejemplo, la enorme y compleja carga de subjetividades y sentidos que contiene la memoria. Para acercarse a esta dimensión, el autor italiano señala que es indispensable la reflexión del testigo (en nuestro caso, la de la víctima), portador de una experiencia inaccesible a los investigadores:

Allí donde el historiador no ve más que una etapa dentro de un proceso, que un aspecto de un cuadro complejo y dinámico, el testigo puede capturar un acontecimiento crucial, el sacudimiento de una vida. El historiador puede descifrar, analizar y explicar las fotos conservadas de Auschwitz. Sabe que son judíos los que descienden del tren, sabe que el SS que los observa participará en una selección y que la gran mayoría de las figuras de esa foto no tienen ante sí más que algunas horas de vida. A un testigo, esa foto le dirá mucho más; le recordará sensaciones, emociones, ruidos, voces, olores, el miedo y el desconcierto del recién llegado al campo, la fatiga de un largo viaje efectuado en condiciones horribles, quizás la visión de la chimenea de los crematorios. En otros términos, un conjunto de imágenes y recuerdos absolutamente singulares y completamente inaccesibles al historiador si no es a partir de un relato a posteriori, fuente de una empatía incomparable con la que pudo haber revivido el testigo. (p. 6)
El Amovi no solo ha seguido la pauta sugerida por Traverso (2007), implicando a las víctimas en la construcción de memoria y conservando sus voces con criterios archivísticos, sino que, además, ha agregado un momento nuevo ante esta construcción, a saber, el intento de que estas víctimas contextualicen, comprendan y se aproximen a lo sucedido desde elementos de las ciencias sociales, es decir, que obtengan elementos críticos de sus propias memorias y así tanto ellas como la sociedad colombiana en general se hagan partícipes de un conocimiento histórico y sociológico que les sirva para la lucha y la transformación del país. Esta labor política del Amovi es a su vez una posibilidad académica de valiosísima importancia, pues organizar y resguardar voces de víctimas en un contexto de sistemática desaparición y destrucción de archivos (Molano, 2015) o de recurrente captación de archivos personales y colectivos por entes estatales ${ }^{9}$ no solo democratiza el conocimiento sino que además lo fomenta.

\section{El trabajo del Amovi}

Dentro de las actividades llevadas a cabo por el Amovi, pueden destacarse las siguientes: realización de entrevistas a víctimas, elaboración de trayectorias de vida, acopio, clasificación y conservación de fondos documentales, organización de talleres de formación y producción de eventos y actividades

9 Nos referimos a las acciones adelantadas por la División de Archivos de Derechos Humanos del Centro Nacional de Memoria Histórica (CNMH), que ha venido centralizando en Bogotá archivos de distintas organizaciones sociales regionales, con la pretensión de crear un gran archivo nacional. Una actuación similar ha venido realizando la Dirección de Museos. Si bien este actuar puede ser bien intencionado, 10 cierto es que margina a las regiones, que son los territorios más afectados por el conflicto, de instrumentos de socialización tan influyentes, en lo relacionado con la memoria, como los archivos y museos. 
conmemorativas o de difusión. A continuación, se hará alusión a la forma como se han desarrollado algunas de estas actividades y las dificultades que han implicado.

\section{Las entrevistas}

Las entrevistas han constituido la principal labor y fuente de investigación en el Amovi. La estrategia de los investigadores para conseguir este material, después de acercarse a los barrios y de presentar el proyecto a las distintas asociaciones y líderes comunitarios, ha sido generar un ambiente de confianza a las víctimas interesadas en participar, insistiendo en la importancia que tienen sus historias de vida en la construcción de memoria del conflicto y de la potencialidad de sus relatos como alternativas documentales para la comprensión de la historia reciente del país y el cumplimiento efectivo de los derechos a la verdad, reparación y garantías de no repetición.

En el proceso de invitación, muchas víctimas se negaron a narrar sus experiencias aduciendo temores y desconfianzas, factores no del todo inesperados por los investigadores, máxime en un país que aún vive el conflicto y en el que las amenazas se ciernen sobre las víctimas de forma permanente sin importar cuánto se hayan esforzado por alejarse de ellas. Las víctimas temen hablar de lo que les pasó, temen revelar nombres o datos que les signifiquen ser juzgados o señalados como los responsables de su propia tragedia, o ponerse nuevamente en situación de riesgo. Por eso, quienes finalmente aceptaron narrar sus historias de vida vencieron sus miedos y reconocieron la importancia de apostarle a la lucha por la memoria a través de la divulgación de sus propias vivencias.
Además de los temores y recelos, las condiciones de vida adversas también han sido una dificultad constante en la mayoría de las víctimas entrevistadas, pues esta situación obstaculiza los trabajos académicos y político-reflexivos con ellas. La falta de empleo, la precariedad de las viviendas (muchas veces acompañada de hacinamiento), la falta de atención médica y las secuelas físicas y psicológicas dejadas por el conflicto constituyen una amalgama de problemas que requieren soluciones inmediatas y que complican, por tanto, volcar el pensamiento hacia asuntos transcendentales de la sociedad, o históricos o futuros. No obstante, a pesar de este tipo de problemas, los relatos obtenidos dan cuenta de que las víctimas pueden ir más allá del dolor y del sufrimiento, y mantener en sus vidas un espíritu de esperanza, resistencia y lucha a veces inquebrantable.

En lo que respecta al ejercicio narrativo como tal, cada entrevistado, a su manera, seleccionó datos, imágenes, diálogos, episodios y personajes que le ayudaron a construir su relato de vida. En las entrevistas, realizadas muchas veces en sus propios hogares, los entrevistados contaron su infancia, los recuerdos de sus padres y demás familiares, ${ }^{10}$ así como las anécdotas más significativas de los lugares donde crecieron. Describieron también el dolor y la zozobra producida por la victimización, las

10 Sobre las memorias familiares, Da Silva señala lo siguiente: "La memoria familiar es un laboratorio de ideas y recursos, para imaginar y reconstruir aquello que en una nación se produce y construye en torno a la idea de memoria, a lo que se recuerda, lo que se silencia u olvida. Producto de la interacción y construcción entre la subjetividad de los individuos y las normas colectivas, sociales, políticas, religiosas y jurídicas, el trabajo de la memoria fabrica las identidades sociales, enunciando tanto lazos de pertenencia como relaciones de diferenciación" (2007, p. 1). 
adversidades y los nuevos comienzos después de la tragedia. La angustia, el miedo, la rabia, el desconsuelo, impregnan cada una de las entrevistas, pero también la fortaleza, la resistencia, la convicción y la entrega a causas nobles, que muchas veces superaron los intentos de los victimarios por la anulación y el olvido. Las entrevistas fueron, en últimas, intensos ejercicios de reconstrucción de la historia individual y colectiva, es decir, un lugar para el posicionamiento identitario.

El objetivo de la investigación era mostrarles a las víctimas las posibilidades de comprensión del conflicto en cada uno de sus relatos, con la clara intención de entender y analizar el pasado siempre ante el futuro. Por eso sus voces no solo evocan y desahogan tristezas, sino que también reflexionan, cuestionan y reclaman; sus voces piensan un devenir diferente en el mismo país que ha tratado de borrarlas. Estas personas han entendido que la lucha por la justicia y la verdad es necesariamente también la lucha contra el olvido.

\section{Las trayectorias de vida}

El proceso de elaboración de trayectorias de vida llevado a cabo por el Amovi ha sido abordado en otro artículo (Escamilla y Novoa, 2017a). Con esta metodología, se han construido 55 trayectorias de vida publicadas en dos libros: el primero, Voces contra el silencio, memoria contra el olvido (Suárez, Novoa, Ardila, Rueda y Oyola, 2013), contiene 25 trayectorias de víctimas de desplazamiento forzado; el segundo, Trayectorias de dolor y resistencia (Suárez, Escamilla, Novoa, Díaz y Rojas, 2017), 30 trayectorias de víctimas de diversos hechos victimizantes.
La apuesta por las trayectorias de vida responde al interés de dar a conocer las historias, las vivencias y los sentimientos expresados en las entrevistas a una población más amplia que la mera comunidad académica. Se buscó que estas trayectorias permitieran mostrar las realidades de un conflicto que para muchos colombianos pasa desapercibido o les es indiferente, con el fin, no solo de generar cierta sensibilidad frente al drama humano dejado por la guerra, sino también de hallar un eco cada vez mayor en la ciudadanía colombiana frente a los reclamos de verdad, justicia y reparación de las víctimas. En esta línea, es muy pertinente citar a Giraldo, quien explica su decisión de contar las historias de personas víctimas y no reducirse a la caracterización de fenómenos amplios:

Sé bien que los análisis globales son siempre fríos, aunque se refieran a dramáticas situaciones humanas, y que es difícil entender una realidad distante mientras ésta no haga referencia a personas, lugares, fechas y circunstancias. Por eso prefiero escoger aquí, entre muchos millares de casos, algunos de aquellos a los cuales me acerqué personalmente, ya sea porque conocí a las mismas víctimas, ya porque seguí de cerca el dolor de familiares, amigos y comunidades enteras durante el proceso de las denuncias y en la búsqueda de una justicia imposible. (1994, p. 6)

De este modo, y sin renunciar a la pretensión de hacer investigación y análisis rigurosos de los testimonios, las trayectorias de vida permiten dar a conocer las historias de las víctimas de una forma más amplia, sin que dejen de existir, claro está, problemas 
metodológicos. Uno de estos problemas, en primer lugar, es la temporalidad que manejan los entrevistados, temporalidad que no necesariamente es lineal ni sigue la misma cronología de los tiempos históricos de mayor envergadura, pues en las narraciones se presentan saltos o retrocesos, silencios y olvidos que, en últimas, configuran el diseño de un esquema temporal propio, en el que la organización o forma en que se presentan los hechos (y las reacciones a ello) expresan la dimensión individual de la memoria, que no es tampoco absolutamente individual, ya que no deja de contener aspectos colectivos, comunitarios o locales. Pero lo más importante que queremos resaltar de estas temporalidades individuales son sus significativas varianzas con respecto a esquemas de tiempo más generalizados relativos a ámbitos como el país, la nación, el continente o el planeta. Pollack plantea esta organización del tiempo individual/colectivo de la siguiente manera:

La memoria también sufre fluctuaciones que están en función del momento en que resulta articulada, en que está siendo expresada. Las preocupaciones del momento constituyen un elemento de estructuración de la memoria [...] este último elemento de la memoria - su organización en función de las preocupaciones políticas y personales del momento- muestra que la memoria es un fenómeno construido [...] lo que la memoria individual guarda, recalca, excluye, recuerda, es evidentemente el resultado de un verdadero trabajo de organización. Si podemos decir que, en todos los niveles, la memoria es un fenómeno construido social e individualmente, cuando se trata de la memoria heredada podemos decir también que hay una relación fenomenológica muy estrecha entre la memoria y el sentimiento de identidad. (2006, p. 38)

De este modo, las trayectorias de vida representan una alteración (o reorganización) respecto de los tiempos que se exponen en las entrevistas, ya que ordenan todos los eventos narrados en forma cronológica para que sean mejor comprendidos por los lectores. Un segundo problema de las trayectorias de vida es la necesaria ocultación de los nombres de personas y lugares que han sido mencionados en las entrevistas. Este trabajo de edición obedece a la necesidad de proteger la identidad de los narradores, reconociendo que nos encontramos todavía en escenarios de conflicto en los que las personas entrevistadas corren el riesgo de ser revictimizadas. Los nombres en las trayectorias de vida que han sido realizadas por el Amovi han sido sustituidos por simples ella o él según el caso. La decisión de no mencionar nombres incluyó la no referencia toponímica de ciudades o regiones donde ocurrieron los hechos victimizantes. Esta disposición, enmarcada también dentro de la preocupación por salvaguardar la integridad física y emocional de los entrevistados, dificultó enormemente la posibilidad de hacer contextos en cada trayectoria de vida que coadyuvaran al lector a la comprensión de los sucesos narrados. Para subvencionar esta limitante, se procedió a hacer contextos de regiones amplias, como el Magdalena Medio o el Área Metropolitana de Bucaramanga, dentro de las cuales se sucedieron un número significativo de hechos de violencia narrados en las entrevistas. 
Un tercer y último problema en la realización de estas trayectorias de vida consiste en el difícil manejo de la relación objetividad/subjetividad, algo que cualquier investigador que hace uso de la historia oral reconoce como una característica natural de esta forma de hacer historia. Las trayectorias elaboradas por el Amovi resaltan los datos más particulares de las entrevistas, las historias propias de cada narrador, pero también, detrás de cada una de estas historias, si se agudiza la observación, está la historia de la región, del municipio y del mismo país. No obstante, para facilitar mejor la exposición de esta dicotomía entre lo particular y lo general, el proyecto ha primado en las trayectorias de vida el despliegue de las historias individuales, con sus detalles puntuales, sus emociones y cadenas de sucesos propios, mientras que, en lo que respecta a la comunicación de los fenómenos sociales más generalizantes, se han preferido los informes de análisis categoriales, las ponencias en eventos académicos y los artículos científicos.

Entre los fenómenos sociales más resaltados en las entrevistas, caben destacar el rol del Estado, no solo como ausente en la garantía de los derechos de las víctimas, sino también como agresor y su evidente connivencia con grupos paramilitares; la violencia contra las mujeres en todas las esferas de la vida pública y privada; la tenencia de la tierra y la persecución a las opciones políticas de oposición como causa de victimización y revictimización, entre otros. A propósito, Bertaux señala el papel de las fuentes orales $\mathrm{y}$ de las historias individuales en la comprensión de este tipo de fenómenos:

Y, si una vez delimitado claramente el carácter de lo que se encuentra en numerosos casos, parece que se trata de un "objeto sociológico" - una norma, una obligación social, un papel a desempeñar, un proceso, el efecto de una relación estructural, etc. - , es decir que se trata de algo que se desprende de lo social y no de lo psicológico, de lo colectivo y no de lo individual, entonces puede afirmarse que se ha alcanzado un primer nivel de saturación. Dicho de otro modo, se tiene la seguridad de haber identificado un fenómeno que no sale ni de la imaginación (en el sentido de propensión a crear fantasmas) de los investigadores, ni de la del interlocutor mitómano: allí está lo social que se expresa a través de voces individuales. (1989, p. 7)

Esta potencialidad sociológica de las entrevistas no ha impedido que el Amovi señale hechos puntuales cuando la ocasión lo amerita (masacres, bombardeos, violaciones sexuales, desapariciones forzadas, torturas, homicidios, etc.), si bien en muchas oportunidades ha sido imposible darles a estos acontecimientos un manejo más minucioso de seguimiento judicial, por exceder los objetivos y las capacidades del proyecto. Esperamos que en un futuro no muy lejano este material del Amovi sirva como soporte en los adelantamientos que está tratando hacer hoy la justicia transicional a favor de las víctimas.

\section{Un archivo de memoria de víctimas en medio de la guerra}

Además de difundir las historias de los entrevistados, los resultados y el proceso mismo de investigación, la puesta en marcha del Amovi busca la consolidación de un conjunto de fondos documentales que 
permita a otros investigadores, a las víctimas y a la sociedad colombiana en general adelantar sus propios procesos de memoria. La permanencia del conflicto y los peligros que esto encarna para los narradores y trabajadores de la memoria han llevado a la necesaria anonimización de las entrevistas ${ }^{11}$ y a la reserva total de los audios, fotografías y datos personales de los testimonios. De igual forma, la consulta solo puede realizarse de forma presencial en el archivo, luego del diligenciamiento de los formatos de consulta respectivos.

Somos conscientes de que lo anterior, si bien se justifica bajo el propósito de evitar o disminuir la exposición de los entrevistados, va en contravía del objetivo de visibilizar los hechos narrados y las víctimas mismas. Estas contradicciones hacen parte de la compleja realidad en la que se enmarca el proyecto y determinan, no pocas veces, las decisiones por tomar dentro de la dualidad visibilizar y proteger: visibilizar el dolor, la resistencia y las acciones de violencia, sus lógicas, causas y efectos, al tiempo que se reservan los nombres y datos de quienes han hecho posible esta visibilización. Giraldo sostiene al respecto:

El hecho de que la inmensa mayoría de las víctimas del conflicto, cuyos derechos a la vida, a la integridad personal y a la libertad han sido negados, sean personas no combatientes y ajenas a opciones de lucha armada, revelándose así las macro-dimensiones de la criminalización de la protesta y del inconformismo social, crea necesariamente condicionantes a la libertad de

11 Nos referimos a las transcripciones escritas, que es el formato en el que se pueden consultar las entrevistas. pensamiento, de opinión y de opciones ideológicas y políticas, las cuales deben confrontarse necesariamente con el riesgo de perder la vida, la integridad, los medios de subsistencia y la libertad, llevando a que sean minorías cada vez más reducidas las que asuman esos riesgos y sostengan posiciones éticas que se proyecten en cambios sociales. (2016, p. 463)

\section{Las múltiples expresiones de la memoria}

El Amovi es un archivo oral que ha apelado a la oralidad, no solo por ser una innovación metodológica interesante, sino por constituir una apuesta real para hacer la memoria del conflicto desde las víctimas, quienes, no hay duda, poseen en sus voces los elementos vivenciales más importantes para aportar a la verdad. De este modo, tal como lo afirma Portelli, las fuentes orales, no solo connotan aportaciones cognitivas, sino también un significativo espíritu democrático:

¿Por qué buscamos fuentes orales? ¿Por qué trabajamos con ellas? No solo porque las personas que entrevistamos poseen informaciones que precisamos, que nos interesan. Es más que eso. Es porque existe una relación profunda, una relación muy intensa, entre la oralidad y la democracia. Todos los medios de comunicación, desde el escáner a la computadora, excluyen a una parte de la humanidad. Hay personas que no saben escribir o leer, hay personas que no manejan la computadora; pero tienen la voz, la oralidad, es un medio de comunicación que todos los seres humanos poseemos y, de alguna manera, controlamos. Entonces, cuando buscamos 
fuentes orales, las buscamos en primer lugar porque en la oralidad encontramos la forma de comunicarse específica de todos los que están excluidos, marginados, de los medios y del discurso público. Buscamos fuentes orales porque queremos que esas voces - que sí, existen, aunque pocos o ningunos las escuchen - tengan acceso a la esfera pública, al discurso público y que lo modifiquen radicalmente. $(2009$, p. 2)

Esta relevancia de las fuentes orales, sin embargo, no tiene por qué desestimar otros tipos de documentos que también son construidos por las víctimas, tales como cartas, denuncias judiciales, diplomas, fotografías, objetos, entre otros elementos que la gente conserva como vestigios de lo que ha sido su propia historia (hay que considerar, además, que los documentos escritos han sido la forma predominante como las organizaciones sociales y de víctimas han buscado registrar sus procesos y legados). Por estas razones el Amovi, como institución archivística, ha realizado una labor de acopio en la que, además de los testimonios orales, los fondos documentales son nutridos con cuadernos, expedientes, fotografías, informes, actas, correspondencia personal e institucional, etc., otorgándoles a las fuentes orales recursos complementarios muy importantes.

\section{La difusión y los lugares de memoria}

En el Amovi, la tarea de hacer memoria del conflicto armado en Colombia ha sobrepasado el mero hecho de hacer entrevistas y construir trayectorias de vida. Este trabajo intelectual y académico ha venido transcendiendo mediante acciones que intervienen el espacio, entre las cuales, las más importantes son, en primer lugar, la disposición de un lugar físico para el archivo dentro del campus de la UIS y, en segundo lugar, las marcas de memoria que este archivo ha venido imprimiendo en algunos sitios de la ciudad de Bucaramanga y de la UIS. Entendiendo los lugares de memoria como espacios o símbolos de "convocatoria concentrada del recuerdo", como los llamó Nora (2008, p. 33), es evidente que estos lugares deben llevar consigo una intencionalidad y que dicha intencionalidad está mediada por intereses y marcos sociales. Nora señala:

Pues, si bien es cierto que la razón de ser fundamental de un lugar de memoria es detener el tiempo, bloquear el trabajo del olvido, fijar un estado de cosas, inmortalizar la muerte, materializar lo inmaterial para [...] encerrar el máximo de sentidos en el mínimo de signos, está claro, y es lo que los vuelve apasionantes, que los lugares de memoria no viven sino por su aptitud para la metamorfosis, en el incesante resurgimiento de sus significaciones y la arborescencia imprevisible de sus ramificaciones. (2008, p. 34)

Da Silva también resalta el carácter dinámico y controversial de los lugares de memoria y denomina las disputas que por los sentidos del pasado se ciernen sobre ellos territorios de memoria. Según la autora,

esta noción abría los sentidos y las clasificaciones sobre el pasado en clave de conflicto. Enfatizaba la conquista, el litigio, la extensión de las fronteras y sobre todo la disputa. Allí donde el Estado había impuesto con decretos y leyes el perdón y el olvido, diversos 
grupos e instituciones respondían con una batalla por la memoria y la verdad. (2014, p. 30)

En el Amovi, la idea de elaborar marcaciones y construir lugares de memoria en la ciudad de Bucaramanga surgió a partir del ejercicio de memoria que distintos grupos sociales, culturales y políticos de la ciudad habían empezado a realizar inspirados en el legado del poeta Jesús María Peña, más conocido en su momento como Chucho Peña, quien fue desaparecido y posteriormente encontrado muerto, con signos de tortura, en 1986. La obra de Chucho y su actividad como artista y militante político ha sido la referencia de una generación que fue exterminada en una de las épocas de mayor despliegue del terrorismo de Estado en Colombia (década de los ochenta). Los sobrevivientes de tan ignominioso periodo han buscado, por tanto, que las nuevas generaciones posicionen el recuerdo de este poeta en relación con un pasado de lucha y movilización social, que ciertos sectores de la ciudad de Bucaramanga han propendido a olvidar de manera absoluta. El Amovi se ha unido al movimiento en torno a la memoria de Chucho Peña y, sin duda, dado su carácter institucional universitario, lo ha potencializado en la ciudad.

Esta confluencia de esfuerzos ha implicado varias tareas para el Amovi. En primer lugar, la de investigar y conocer a mayor profundidad la historia de Chucho Peña. Para ello, se han realizado entrevistas a personas que lo conocieron en vida y que también vivieron los momentos posteriores a su asesinato. Gracias a estas pesquisas, a los testimonios recolectados y a la lectura de su obra, el equipo de trabajo del Amovi ha considerado relevante, no solo conmemorar los aniversarios de la muerte del poeta, sino también realizar una marca de memoria en el lugar donde fue raptado por sus asesinos: la esquina de un céntrico y frecuentado parque de la ciudad (Parque Bolívar).

Fue gracias a estos y otros testimonios que los jóvenes historiadores que hacían sus pasantías de investigación en el Amovi, así como un sector del estudiantado de la UIS y transeúntes de la ciudad, empezaron a descubrir una parte de la historia local que les era desconocida. La memoria en este caso permitió que se resignificaran espacios que hasta ese momento pasaban desapercibidos para la inmensa mayoría de los habitantes y que, por primera vez, se pensara en la ciudad de Bucaramanga como un escenario del conflicto armado, contrario a la idea de que la guerra en Colombia ha estado relegada a las áreas rurales y las ciudades solo han sido receptoras de víctimas.

Además de la marcación del lugar donde inició la desaparición forzada de Chucho Peña, también se han realizado conciertos, recitales de poesía y un mural con el retrato del poeta acompañado de la imagen de Carmenza Landazábal Rosas, una estudiante de Trabajo Social de la UIS desaparecida en 1988 y de quien hasta el momento no se tienen noticias. A estas actividades se sumó la intención de nombrar al Auditorio Menor de la Facultad de Ciencias Humanas con el nombre de la referida estudiante, pero tal iniciativa ha sido constantemente rechazada por las autoridades universitarias $y$ ha significado una pugna permanente en la que, periódicamente, se ponen y se quitan placas con el nombre de la estudiante desaparecida. 
De este modo, se ha dado inicio al proceso de rememoración y homenaje de las víctimas que pertenecían a la comunidad universitaria (estudiantes, profesores y trabajadores) y que en su mayoría estaban arrojados al olvido por parte de la administración de la UIS (quizá con la pretensión de evitar la memoria de un pasado problemático que volviera a desatar reclamos en el presente o sirviera de referente para nuevas luchas). En este contexto, se puede citar el caso del estudiante William Camacho, desaparecido también en 1986, de quien tampoco se tiene rastro y cuyos cuadernos de notas fueron donados por su familia para conformar el acervo del Amovi.

Finalmente, cabe destacar la creación del Sendero de Conciencia, que contiene dentro de su recorrido siluetas de personas cuyos nombres representan a los desaparecidos y asesinados que han hecho parte de la UIS. En él también se han hecho, en colaboración con organizaciones de familiares de detenidos desaparecidos, exposiciones fotográficas de personas víctimas de desaparición forzada y continuos eventos culturales relacionados.

A todas estas acciones se sumó la proyección periódica de documentales de conflictos armados distintos del colombiano, con el fin de que la comunidad universitaria y la ciudadanía local tuviesen una perspectiva internacional de elementos como el paramilitarismo, las insurgencias, el terrorismo de Estado, la desaparición forzada, etc., fenómenos amplios y complejos, que exceden nuestra realidad nacional y tienen una lógica globalizante. Como parte de este ciclo de documentales, se conocieron los casos del genocidio en Indonesia, el exterminio de las Panteras Negras en los Estados Unidos, las dictaduras en Chile y Argentina y el asesinato de Patrice Lumumba en el Congo.

\section{CONCLUSIÓN: CONFLICTOS Y DIFICULTADES}

Ante esta apuesta de memoria, son varias las observaciones que salen a flote. En primer lugar, existe una notable dificultad para que la academia, por lo menos desde nuestra realidad local, adelante esfuerzos en la construcción de una memoria del conflicto armado colombiano que tome distancia de las iniciativas estatales y que, de manera autónoma y objetiva, ingrese a las batallas por el significado del pasado. En el caso del Amovi, esta dificultad puede evidenciarse, pues tanto la UIS como Colciencias, entidades que han financiado y apoyado la creación y consolidación del Amovi, son instituciones estatales que, si bien se permiten alguna independencia de las políticas de los gobiernos de turno y respetan en cierta medida la autonomía de los investigadores, no dejan de estar interconectadas con decisiones que competen exclusivamente al Estado, tales como los asuntos presupuestales, las orientaciones de los proyectos de investigación o los intereses de los representantes que ostentan las investiduras directivas de sus administraciones, para quienes, en muchas ocasiones, dado el relacionamiento político que estos cargos ameritan, los resultados de la investigaciones en fenómenos sociales tan complejos como el conflicto armado interno suelen ser incómodos.

Por otro lado, la lucha por mantener distancia del Estado y condenar sus acciones como victimario del conflicto ha implicado para el Amovi frecuentes debates con representantes del CNMH, entidad estatal encargada 
de llevar a cabo todo el programa de memoria en el país y que recibe el grueso de recursos y herramientas presupuestadas para tal tarea. El Amovi también se ha negado a entregar a sus entes financiadores las listas de personas entrevistadas o sus datos personales, así como los audios y las transcripciones íntegras de las entrevistas, todo esto apelando al carácter de documentación reservada que consta en los inventarios y cuadros de clasificación, así como a lo establecido en el consentimiento informado firmado por las personas antes de cada entrevista.

Una segunda dificultad consiste en llevar adelante una apuesta por hacer memoria junto con las víctimas del conflicto cuando este aún no ha terminado y aún más cuando el llamado no solo es a su narración, sino también a su comprensión crítica, acompañada de reclamos de justicia y verdad al Estado y los victimarios. El manejo de esta problemática sugirió la necesidad de anonimizar las entrevistas transcritas y mantener en total reserva la identidad de los entrevistados, pero, además, ha llevado a tomar medidas como la de no fotografiar rostros de víctimas y evitar al máximo la transmisión de información por internet para evitar filtraciones de cualquier tipo. El Amovi tampoco permite la sustracción de las entrevistas anonimizadas de la sede física del archivo y su consulta debe hacerse en compañía de personal autorizado y previa solicitud aprobada. A los riesgos que la continuidad de la guerra cierne sobre los entrevistados, entrevistadores, acompañantes del proceso y sobre la documentación misma, se suma la dificultad de obtener recursos económicos que garanticen la continuidad del funcionamiento institucional del Amovi en un país donde lo destinado a educación e investigación social es mínimo.

Por otra parte, se destaca la necesidad de encarar las iniciativas y los procesos de memoria desde enfoques críticos que superen visiones abstractas y relativistas de la memoria y que al mismo tiempo susciten la comprensión de los procesos históricos, ya que, si bien narrar hace parte del comprender, se requieren, además, otros elementos que permitan ubicar el relato en contextos y dimensiones sociales más amplios, que traduzcan esta comprensión en recuperación de los proyectos políticos echados a la borda. Esta última pretensión es una crítica al enfoque humanitarista de la memoria, que solo piensa en las víctimas como seres ingenuos y neutrales, o herramientas instrumentalizadas de paz y reconciliación. Sobre estos "usos" de la memoria Pilar Calveiro señala lo siguiente:

Pedir la palabra no siempre es pedir la paz; hay palabra de confrontación, violencia y guerra. ¿Es el testimonio necesariamente una palabra de paz? Creo que, en todo caso, es una palabra que demanda justicia, no tanto en el sentido del derecho como en el sentido ético de la palabra. Y esta justicia, que repara en el Otro excluido o masacrado, sin ser necesariamente guerrera, puede recurrir ella misma a la violencia. El testimonio denuncia una violencia $y$, al hacerlo, desafía y violenta el orden existente de distintas maneras, y este es su mayor interés, desde mi punto de vista. Es en este cruce de memoria, testimonio y justicia, es decir, en la dimensión ética y política de este cruce, donde pretendo colocarme. (2017, p. 1) 
Y finalmente, como parte del análisis de los alcances y las limitaciones del Amovi, tanto en lo teórico como en lo práctico, quedan preguntas que todavía no podemos responder de manera vehemente y que es necesario plantearlas para alimentar el debate: ¿Es posible lograr a través de la memoria la comprensión del conflicto armado y la subsecuente movilización social que encabece o acompañe los reclamos de justicia y garantías de no repetición en Colombia? ¿Cuál es el papel de los historiadores y de la academia en general ante esta posibilidad? $\mathrm{Y}$ esto no solo a partir de las palabras de Calveiro, sino también de las Enzo Traverso, quien en una entrevista realizada en 2008 y publicada en la revista Andamios manifestaba: "La memoria, tal y como se construye en el espacio público y la sociedad civil, suscita una demanda social de conocimiento a la cual la historia es llamada a responder" (Modonesi, 2008).

\section{ReFERENCIAS}

Acevedo Arango, O. F. (2012). Geografías de la memoria: posiciones de las víctimas en Colombia en el periodo de justicia transicional (2005-2010). Bogotá, Colombia: Pontificia Universidad Javeriana.

Archila, M. (2012). Memoria histórica y movimientos sociales. Ponencia presentada en el XVI Congreso Colombiano de Historia: Guerras, regiones y memorias, Neiva, Colombia.

Calveiro, P. (2017). Sentidos políticos del testimonio en tiempos de miedo. En A. Cacopardo, Testimonio y entrevista. Manuscrito no publicado, Maestría en Historia y Memoria, Universidad Nacional de La Plata, Argentina.

Centro Nacional de Memoria Histórica. (2013). ¡Basta ya! Colombia: memorias de guerra y dignidad. Bogotá, Colombia: Autor.

Comité Internacional de la Cruz Roja. (2008). ¿Cuál es la definición de "conflicto armado" según el derecho internacional humanitario? Recuperado de https://www. icrc.org/spa/resources/documents/article/other/armed-conflict-article-170308. htm

Da Silva Catela, L. (2006). Memoria entre el recuerdo y la identidad. Buenos Aires, Argentina: Secretaría de Cultura de la Nación.

Da Silva Catela, L. (2014). “Lo que merece ser recordado...": conflictos y tensiones en torno a los proyectos públicos sobre los usos del pasado en los sitios de memoria. Clepsidra: Revista Interdisciplinaria de Estudios sobre Memoria, 1(2), 28-47.

Escamilla Márquez, D. A. y Novoa Sanmiguel, L. D. del P. (2017a). Conflicto y memoria: trayectorias de vida como metodología para comprender el conflicto armado colombiano. Revista Colombiana de Ciencias Sociales, 8(1), 65-87.

Escamilla Márquez, D. A. y Novoa Sanmiguel, L. D. del P. (2017b). La memoria del conflicto armado en Bucaramanga: análisis de una experiencia investigativa desde las voces de las víctimas. El Ágora USB, 17(2), 324-613.

Estrada, J. (2016). Acumulación capitalista, dominación de clase y rebelión armada. En Comisión Histórica del Conflicto y sus Víctimas, Contribución al entendimiento del conflicto armado en Colombia (pp. 295-360). Bogotá, Colombia: Desde abajo.

Giraldo, J. (1994). Colombia, esta democracia genocida. Barcelona, España: Fundación Lluís Espinal.

Giraldo, J. (2016). Aportes sobre el origen del conflicto armado en Colombia, su 
persistencia y sus impactos. En Comisión Histórica del Conflicto y sus Víctimas, Contribución al entendimiento del conflicto armado en Colombia (pp. 423470). Bogotá, Colombia: Desde abajo.

Jelin, E. (2002). Los trabajos de la memoria. Madrid, España: Siglo XXI.

La administración de la justicia y los derechos humanos de los detenidos. La cuestión de la impunidad de los autores de violaciones de los derechos humanos (civiles y políticos). Informe final elaborado y revisado por $\mathrm{M}$. Joinet en aplicación de la decisión 1996/119 de la Subcomisión. Recuperado de http://www. derechos.org/nizkor/doc/joinete.html

Ley 975/2005, de 25 de julio, por la cual se dictan disposiciones para la reincorporación de miembros de grupos armados organizados al margen de la ley, que contribuyan de manera efectiva a la consecución de la paz nacional y se dictan otras disposiciones para acuerdos humanitarios.

Ley 1448/2011, de 10 de junio, por la cual se dictan medidas de atención, asistencia y reparación integral a las víctimas del conflicto armado interno y se dictan otras disposiciones.

Modonesi, M. (2008). Historia, memoria y política: entrevista con Enzo Traverso. Andamios, 4(8), 245-256. Recuperado de http://www.scielo.org. $\mathrm{mx} /$ scielo.php?script=sci_arttext\&pi$\mathrm{d}=$ S1870-00632008000100010

Molano, J. (2015). Archivos de quién... Ponencia presentada en el Primer Seminario
Internacional: Memoria histórica y archivos orales en el marco de conflictos armados, Bucaramanga, Colombia.

Nora, P. (2008). Les Lieux de Mémoire. Montevideo, Urugual: Trilce.

Pollak, M. (2006). Memoria, silencio y olvido: la producción social de identidades frente a situaciones límite. La Plata, Argentina: Al Margen.

Portelli, A. (2009). Historia oral y poder. Ponencia presentada en XXV Simpósio Nacional de História: História e Ética, Fortaleza, Brasil.

Suárez Pinzón, I., Ardila E., Báez, J. S. y Rueda, J. F. (2010). Estudio de trayectorias de vida de personas en situación de desplazamiento forzado interrelacionadas en el barrio Café Madrid del municipio de Bucaramanga. Bucaramanga, Colombia: Universidad Industrial de Santander.

Suárez Pinzón, I., Escamilla, D., Novoa, D., Díaz, L. y Rojas, L. (2017). Trayectoria de dolor y resistencia. Bucaramanga, Colombia: Universidad Industrial de Santander.

Suárez Pinzón, I., Novoa S., D. del P., Ardila S., E. E., Rueda A., J. F. y Oyola V., A. X. (2013). Voces contra el silencio, memoria contra el olvido. Bucaramanga, Colombia: Universidad Industrial de Santander.

Traverso, E. (2007). Historia y memoria: notas sobre un debate. En M. Franco y F. Levín (Eds.), Historia reciente: perspectivas y desafíos para un campo en construcción (pp. 67-97). Buenos Aires, Argentina: Paidós. 